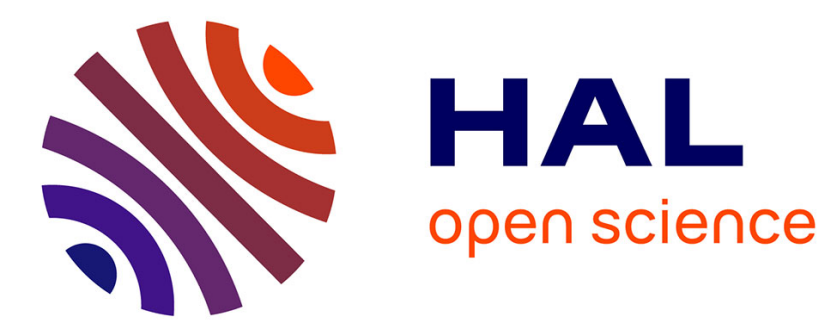

\title{
Young adults living apart and together (LAT) with parents: A three level analysis of the Italian case
}

Francesco C. Billari, Alessandro Rosina, Rita Ranaldi, Clelia Romano

\section{To cite this version:}

Francesco C. Billari, Alessandro Rosina, Rita Ranaldi, Clelia Romano. Young adults living apart and together (LAT) with parents: A three level analysis of the Italian case. Regional Studies, 2008, 42 (05), pp.625-639. 10.1080/00343400701543173 . hal-00514680

\section{HAL Id: hal-00514680 \\ https://hal.science/hal-00514680}

Submitted on 3 Sep 2010

HAL is a multi-disciplinary open access archive for the deposit and dissemination of scientific research documents, whether they are published or not. The documents may come from teaching and research institutions in France or abroad, or from public or private research centers.
L'archive ouverte pluridisciplinaire HAL, est destinée au dépôt et à la diffusion de documents scientifiques de niveau recherche, publiés ou non, émanant des établissements d'enseignement et de recherche français ou étrangers, des laboratoires publics ou privés. 


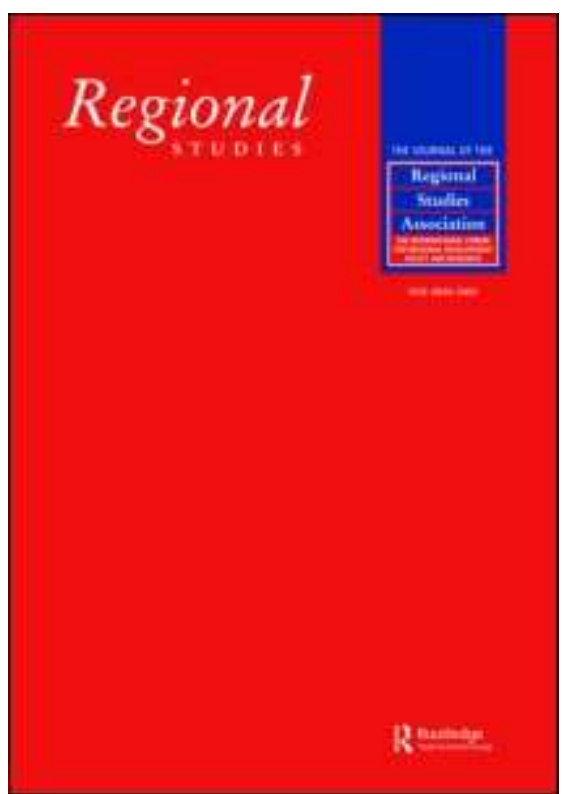

\section{Young adults living apart and together (LAT) with parents: A three level analysis of the Italian case}

\begin{tabular}{|r|l|}
\hline Journal: & Regional Studies \\
\hline Manuscript ID: & CRES-2005-0269.R2 \\
\hline Manuscript Type: & Main Section \\
\hline JEL codes: & $\begin{array}{l}\text { J13 - Fertility|Family Planning|Child Care|Children|Youth }<\text { J1 - } \\
\text { Remographic Economics }<\text { J - Labor and Demographic Economics, } \\
\text { Household Analysis }<\text { R - Urban, Rural, and Regional Economics }\end{array}$ \\
\hline Keywords: & Italy, LAT, leaving home, multilevel models \\
\hline &
\end{tabular}

\section{SCHOLARONE" Manuscripts}




\title{
Young adults living apart and together (LAT) with parents:
}

\section{A three level analysis of the Italian case}

\author{
Authors: Francesco C. Billari, Alessandro Rosina, Rita Ranaldi and Maria Clelia \\ Romano \\ Francesco C. Billari, Carlo F. Dondena Centre for Research on Social Dynamics, IMQ \\ and IMQ, Università Bocconi, Viale Isonzo 25, 20135 Milano, Italy. E-mail: \\ francesco.billari@unibocconi.it
}

\begin{abstract}
Alessandro Rosina, Institute of Demographic Studies, Università Cattolica del Sacro Cuore, Milano and Carlo F. Dondena Centre for Research on Social Dynamics, Largo Gemelli 1, 20123 Milano, Italy. E-mail: alessandro.rosina@unicatt.it
\end{abstract}

Rita Ranaldi, ISTAT (Istituto Nazionale di Statistica), Via Adolfo Ravà 150, 00124 Roma, Italy. E-mail: $\underline{\text { ranaldi@istat.it }}$

Maria Clelia Romano, ISTAT (Istituto Nazionale di Statistica), Via Adolfo Ravà 150, 00124 Roma, Italy. E-mail: romano@ istat.it 


\title{
Young adults living apart and together (LAT) with parents:
}

\section{A three level analysis of the Italian case}

\begin{abstract}
In this paper we introduce the notion of living apart together (LAT) with one's parents as a status in the transition to adulthood. We define LAT with parents as the situation in which young adults who reside with their parents spend a significant amount of that time living outside the parental household. We describe young adults who LAT with parents and analyse the determinants of LAT with reference to Italy. We document the relevance of this phenomenon for Italy, a country with one of the highest share of young adults cohabiting with parents and with fundamental subnational differences both on higher education provision and in labour market situation. We analyse official survey and census data and we use a multilevel statistical model to analyse the determinants of the LAT choice, with individuals, households, and municipalities as levels.
\end{abstract}

Keywords: LAT, leaving home, youth, multilevel models, Italy.

JEL Classification: R23, J13.

Word count (main text): 7,359 


\section{Introduction}

Nowadays, no single event marks the passage from youth to adulthood. In other words, we cannot consider the attainment of any single status as indicating that adulthood has been reached. The transition to adulthood in contemporary societies is a gradual process in which individuals experience on the one hand the subjective feeling of having become an adult, on the other hand the objective involvement in roles that are typical of adults. The latter involvement is marked by life course events, such as leaving full time education, entering the labour force, leaving the parental home, marrying and becoming a parent (Modell et al., 1976).

In this paper we discuss a type of residential choice that we define as Living Apart and Together (LAT) with parents. We focus on documenting the emergence of LAT with parents in Italy and on studying its determinants. In our definition, young adults are LAT with parents if they are living part of the time with their parents and part of the time away from their parents. This usually implies, at least in the Italian setting, that young adults are officially residing (as from population registers) with parents. Among young Italians aged $15-34,10.4 \%$ of men and $8.6 \%$ of women residing with parents can be classified as LAT. This share is particularly high for university students (23.3\% LAT with parents for men and $23.4 \%$ for women), but also sizable for employed young adults (9.3\% LAT with parents for men and $8.6 \%$ for women) - see Table 1.

LAT has been so far discussed as related to couple relationships: LAT couples are living partly together and partly in separated accommodation (see, e.g., Levin, 2004). A related condition has been described in the literature on transition to adulthood as semiautonomy and it is usually attached to participation in higher education or in the 
labour market (Goldscheider and DaVanzo, 1986). However, the main emphasis of the idea of semiautonomy is the (lack of) financial autonomy of young adults, of which residential choices are partly a consequence. In our definition, a young adult who lives apart and together with parents is still considered as LAT even if she/he is financially autonomous. By explicitly defining a LAT relationship with parents, we intend to put the main focus on the actual living arrangement of young people rather than on financial autonomy or on the official place of residence.

Although the crucial importance of living arrangements of young adults is widely recognised, analyses focussing on LAT or semiautonomy are rare. So far, no analysis is available to our knowledge on the determinants of LAT. We contribute to the debate by discussing the emergence and the determinants of LAT with reference to a peculiar case: $\underline{\text { Italy. }}$ The Italian case deserves a specific discussion, which we shall widen later in this paper. Young Italians belonging to recent cohorts have extremely high rates of coresidence with their parents when compared to their peers residing in other Western countries. Also because of this peculiarity, coresidence with parents has been investigated more in detail during recent years. The Multipurpose Survey on "Households, Social Subjects and Childhood Conditions", conducted in 1998 by the Italian National Institute of Statistics contained for the first time data allowing the study young adults who are LAT with parents. We study Italian women and men aged 15-34 who are officially resident with their parents, and we put a specific emphasis on a three level explanatory model, with factors at the individual, household, and municipality level. To this purpose, we link individual data with meso level data on the household (as available from the same survey) and on the municipality of residence of parents (as available from official statistics), and we use a multilevel statistical model. More 
specifically, our analyses focus on two groups of young adults: 1) university students: $19.2 \%$ of them are LAT with parents (only $4 \%$ of university students in Italy do not reside officially with their parents); 2) employed young adults (48.8\% of the employed young adults aged 15-34 are officially resident with their parents).

The paper is organised as follows. In section 2, we outline a framework for the analysis of LAT with parents based on the existing literature. In section 3, we review studies on living arrangements of young adults in Italy and introduce a multilevel reasoning on determinants. In section 4, we outline our empirical hypotheses. Section 5 describes the data we use and discusses some descriptive results. In section 6 we introduce the statistical model. Results are presented and discussed in section 7. Section 8 contains some final remarks and a discussion.

\section{TABLE 1 ABOUT HERE}

\section{Background}

In a seminal study on the trajectories of young adults in the United States, Goldscheider and DaVanzo (1986) introduced the notion of semiautonomy as an important step in the transition to adulthood. Semiautonomy refers to the ambiguous living arrangements of those who live in institutional or group quarters, and to their real (lack of) financial autonomy in the absence of welfare support. Semiautonomy is clearly connected to Living Apart and Together (LAT) with parents, which we however explicitly define as a residential choice (not necessarily connected to financial dependence with parents). Semiautonomy is clearly not limited in geographical scope to countries with weak welfare provision such as the U.S.: Villeneuve-Gokalp (2000) for instance, documents 
the spread of semiautonomous living arrangements among French young adults. The emergence of semiautonomous living arrangements, LAT with parents, is also signalled by the fact that leaving home is no longer perceived as being irreversible: returning to the parental home is becoming frequent (Jones, 1995).

From another perspective, the European network of youth researchers EGRIS (Walther et al., 2002) has identified a yo yo structure of gender specific transitions. This structure is associated with tensions and conflicts between roles of youth and roles of adulthood that can be distinguished along three typologies, for which we give examples that are relevant to our case: 1) "divided lives" when qualities of life attributed to youth and adulthood are simultaneously experienced (e.g., being in education while being residentially autonomous); 2) "pending lives" of young people being or wanting to be neither youth nor adult (e.g., being a full time worker but do not perceive oneself as an adult because of perceived job instability); 3) "swinging lives" attempting to alternate between classic biographical phases (e.g., young adults who move back to their parents as a consequence of labour market problems). LAT with parents is therefore consistent with the "yo yo" view of transitions to adulthood. In our view, contingent on an individual's situation, one of the three typologies of conflicts between youth and adulthood indicated by EGRIS prevails for young adults who LAT. The latter can also be interpreted as an additional "sandwich" phase between youth and adulthood (Cavalli and Galland, 1995).

The emergence of LAT with parents can be placed in a broader theoretical framework thanks to a series of theoretical pieces developed within sociology and psychology that address contemporary developments in the transition from youth to adulthood (see e.g. Elzinga and Liefbroer, 2006). The spread of new behaviours in the life course or of 
behaviours that were relatively rare in the past is an hallmark of the process that characterises the evolution of Western European and North American societies towards a new modernity (see e.g., Buchmann, 1989; Beck, 1992; Giddens, 1990). Buchmann (1989) discusses the importance of both institutionalisation and individualisation in shaping the transition to adulthood in contemporary societies. We argue that LAT with parents is pushed both by institutionalisation and individualisation. Moreover, its emergence can be favoured by practices rooted in history.

Institutionalisation (Mayer and Müller, 1986) refers to the increasing importance of calendars and trajectories for the lives of young adults that are imposed by the state and other sources of legal norms. The main example of institutionalisation affecting the transition to adulthood is educational expansion, with the rise of university enrolment, and the subsequent higher relevance of constraints posed by educational systems on the life of young adults. LAT with parents can therefore be expected as an "institutionalised" emerging practice because of educational expansion and because of the need to share the costs of such expansion with the family of origin of students.

Individualisation is at the heart of the work of Beck and Beck-Gernsheim (Beck, 1992; Beck and Beck-Gernsheim, 1995; 2002). Valentine (2003) explicitly builds a theoretical framework on the transition to adulthood based on Beck's individualisation theories, while Schizzerotto and Lucchini (2002) provide a critical view on the individualisation thesis as applied to the transition to adulthood. Within an individualisation hypothesis, we can see the new modernity in which individuals are living in the Western world as creating a shift in both subjective and objective components of the transition to adulthood. For what concerns the "objective" side of statuses experienced by young adults, a wider set of choices can be considered as available. Several processes 
contribute to the enlargement of the choice set: normative pressure on such choices is weakening; traditional forms youth used to get information (e.g., expert knowledge) are eroded; the life course, and therefore youth, are no longer organised only around work. As a consequence, trajectories and statuses that were not present in the past emerge in individual life courses. LAT with parents may be considered one of such statuses.

On the subjective side, in Beck and Beck-Gernsheim framework, like in Giddens, life planning is seen as gaining salience in the life of young people, even if the surrounding environment is not necessarily favourable for the realisation of planning. Being able to plan successful trajectories is seen as an important skill of youth. The risk of failure thus needs to be accounted for in the planning process. LAT may thus constitute a stage during which youth are able to plan and explore opportunities while minimising risk taking. Parental support becomes essential in this stage.

While we here consider LAT with parents as a new emergent practice linked to individualisation and institutionalisation, an historical caveat is necessary. When taking a long term perspective, LAT with parents might not appear as completely new. During the $18^{\text {th }}$ and $19^{\text {th }}$ Century, for instance, in several parts of Northern and Western Europe, a vast number of young people left the parental home in order to work as a servant. This phenomenon gave rise to what Laslett (1997) defined the "life cycle servant". Life cycle servants were highly residentially mobile, even if in many cases they did not work far away from parents moving around in the local labour market (see, e.g., Lundh, 2003). Some life cycle servants were thus likely to spend time LAT with parents, although this status is not clearly documented in the existing literature. For the remainder of this paper it is important to notice that in some European societies, and specifically in Italy, the presence of life cycle servants in the past, and therefore the possibility to observe 


\section{The Italian case: a multilevel framework}

Young Italians leave the parental home at the latest ages recorded in Europe (see, e.g., Cavalli and Galland, 1995; Billari et al., 2001; Walther et al., 2002). In 1988 (according to the same official data source we shall use in our analyses), $99 \%$ of young adults aged 15-19 live with at least one parent. The share of young adults living with parents is $89 \%$ for ages $20-24$ ( $84 \%$ for men, $84 \%$ for women); $60 \%$ for ages $25-29$ (72\% for men, $46 \%$ for women); $23 \%$ for ages 30-34 (30\% for men, $15 \%$ for women). Moreover, the great majority of young Italians leave home only when marrying, and this is likely to influence the peculiarly low fertility levels attained by Italy, with far reaching societal and economic consequences (Billari and Rosina, 2004).

The long stay of young adults in the parental home has long roots in the Italian history (De Sandre, 1988; Barbagli et al., 2003). For such reasons, the study of the living arrangements of young adults is a key issue for demographers who address the "extreme" pattern of family formation that prevails in Italy and its lowest low fertility (see, e.g., Billari et al., 2002). Most of the features of the Italian pattern are also shared by Spain (Holdsworth et al., 2002). As a consequence, when analysing differences within Europe, some scholars have spoken of a "Mediterranean" or "Southern 
European" pattern of leaving home (Cavalli and Galland, 1995; Jones, 1995; Reher, 1998), emphasising above all the underlying cultural roots of the late home leaving and of the strong synchronisation between leaving home and first marriage. The "cultural" argument is based on some historical evidence concerning a tradition of late home leaving or even of lifelong coresidence with one's parents, together with a centrality of marriage consistent with the Catholic religious prevalence (Billari et al., 2001; Dalla Zuanna and Micheli 2004; Holdsworth et al., 2002). In other words, for these scholars the idea of individualisation does not apply, or applies with a temporal lag, to the Italian case. Other scholars (Fernández Cordón, 1997; Esping-Andersen, 1999; Aassve et al., 2001) have emphasised the importance of economic conditions for young adults.

Several explanations can be put forward to explain international differences in patterns of transition to adulthood in Europe (see e.g. Billari, 2004). Nevertheless, the potentially different prevalence of LAT with parents might contribute to an overestimate of the size of differentials. In a recent international comparison on higher education students between 16 countries in the Western world, Italy is the country where the highest share students lives with parents (68\%), while the lowest share of students lives in university residence $(4 \%)$; the remainder of students lives in private accommodation with strong parental support (Educational Policy Institute, 2005). Living in accommodation that is not on campus may also be connected to LAT with parents. Given the peculiarities of the living arrangements of students and housing and late home leaving, LAT can be seen as a key opportunity for Italian youth, and in general for their Southern European counterparts. Indeed, the prevalence of LAT might also have a confounding effect on the interpretation of current behaviours. Given the tradition of outmigration from Italy and Spain, in the case of young workers, this situation can be linked not only to 
financial transfers from parents to young adults, but also to transfers from young adults to their parents.

The theoretical framework we review and adopt suggests considering LAT with parents more as a new opportunity rather than as a constraint. However, access to the new opportunity is subject to constraints that are located at various levels. At the societal level, welfare state, legal regulation and other institutional arrangements regulate the costs and benefits of LAT with parents. For this reason we shall discuss the Italian setting before casting empirical hypotheses on other levels. Factors located at lower levels of aggregation also shape significantly opportunities and constraints connected to LAT with parents. At the regional and/or local level, accessibility and/or affordability of universities and/or of a good labour market constitute discriminating factors in the costs and benefits attached to LAT with parents; cultural differences may also have an influence because the prevailing social norms can be different in different regions and communities. At the lower, household level, cultural and economic factors play a role: LAT with parents, for instance, may become widespread among the forerunners of social change and among privileged social classes.

The literature supports this multilevel view of young adult's choices and opportunities. Analysts often have access to regional level data and therefore emphasise this level. Holdsworth et al. (2002), for instance, describe and explain the reasons for the important regional differentials in leaving home behaviour within Spain, using multilevel statistical models that control for both individual and provincial level characteristics. They argue that economic factors are important at the individual level, while historical traditions of family and household formation are more relevant at the provincial level. For the Italian situation, which is close to the Spanish one in terms of 
overall behavioural pattern, we lack thorough analyses emphasising contextual effects, both at the household and at the community level. A partial exception is the preliminary analysis, using province as a geographical unit, of Borgoni and Billari (2001), where however continuous spatial trends account for most of the variability in the timing of leaving home in Italy.

For what concerns the household level, De Jong et al. (1991), using Dutch panel data, show that a high level of transferable material resources in the parental household, mainly measured in terms of income and property as well as of the father's job, translates into a faster rate of leaving home. In contrast, non transferable material resources such as space in the parental household, the preparation of meals and housework etc, have the opposite effect, as long as leaving home is not due to the continuation of education. Non material resources are also shown to have an impact on the decision of young adults to leave the parental home.

In what follows we modify and extend the essentially multilevel analytical framework developed by Holdsworth et al. (2002) for the analysis of home leaving in Spain in order to 1) focus on LAT rather than on leaving home per se, which implies a focus on young adults who have not yet formed an own family; 2) distinguish analytically three levels: the individual (young adult), the (parental) household, and the local context (municipality of residence of the parental household). The broader regional level will enter only marginally, although significantly as a marker of the prevailing culture with the traditional division of Italy between North-Centre and South-Islands.

\section{Empirical hypotheses}


In this section, we outline the multilevel hypotheses we address in the following empirical analysis. We distinguish our hypotheses according to whether young adults are LAT with parents for study related reasons or for job related reasons. The idea, derived from the theoretical framework we outlined, is that LAT with parents for study related reasons is mainly connected to the opportunity of accessing the university system despite the scarcity of university residences (and of student support). On the other hand, LAT with parents for job related reasons appears to be mainly connected to the problems in the local labour market in the place of origin of young adults-a mix of choice (be connected with the household of origin) and constraint (not finding a suitable job).

\subsection{Students who LAT with parents}

We restrict our first set of analysis and hypotheses to university students aged up to 35 who reside with their parents, and who have and never had an own family. As we said before, in Italy living independently when attending university is a rare situation. More frequently, young students live with their parents if they attend a university which is close enough, or they LAT with them if the university is not sufficiently close (see Table 1). Our main empirical hypotheses for each level are the following.

Individual level. Desires and opportunities for individual autonomy rise with age (see e.g., Buchmann, 1989) — for this reason the propensity to LAT should rise with age. In addition, we hypothesise an interaction between the individual and the community level: being a woman in a traditional context decreases the probability to LAT. The hypothesised gender effects deserve some more discussion. Various studies have 
documented that the prevailing culture in Southern Italian regions (including Islands) puts an important emphasis on female honour (Smith, 1981). Social and cultural anthropologists singled out female honour as a salient value in these regions that is strictly connected to a high gender asymmetry (Viazzo, 2003). Historically, women have not been leaving the parental home before marriage in Southern Italy. Other studies have documented the existence of a greater parental and social control on the behaviour of young women who live with their parents in the South (Rosina and Rivellini 2004). We therefore expect that the emergence of new behaviours is mediated by earlier practices concerning gender discrimination, and therefore that young female students from the region South-Islands have a lower probability to LAT.

Household level. High levels of cultural capital and economic resources of the parental household encourage LAT, as this residential choice may be interpreted as a way to attend a "better" higher education institution, and as it is expensive. Evidence on the role of cultural capital and family endorsement on the residential choices of young adults starting higher education is provided by Patiniotis and Holdsworth (2005).

Municipality level. In Italy, universities are spread all over the country, with some exceptions in South/Islands. Young students whose parents live close to a university will tend to continue residing with their parents, while those who live further away might opt for a LAT living arrangement. Therefore, we assume that living in a community outside urban areas and in the South/Islands (region in which universities are less dense) raises the propensity for a student who resides with parents to be LAT. 


\subsection{Employed who LAT with parents}

In order to cast hypotheses on employed young adults who LAT with parents we first need to recall that in Italy, residing with parents while working is widespread. LAT is then a way to keep the links with the parental home while working in another community, without being a daily commuter. Our main hypotheses on the effects for each level are the following.

Individual level. Our hypotheses here are similar to the case of students: autonomy desires rise with age_LAT propensity should follow this as well. Moreover, being a woman in a traditional context (South-Islands) decreases the probability of LAT.

Household level. As we discussed in the case of students, LAT has a cost, and is a way to enter "softly" the labour market. We therefore hypothesise that a high social status of parents encourages the choice of LAT.

Municipality level. Living in areas with labour market problems raises the probability to LAT, given the need to move to areas with better labour market situation to have higher chances of finding a (satisfying) job. This is consistent with the existing literature on job related individual mobility; for instance, we know that accessibility to job openings in surrounding regions significantly increases the likelihood of choosing commuting versus migration (see e.g. Eliasson et al., 2003). Indeed, LAT can be seen as an intermediate status between daily commuting and migration. In our data, this can be measured with high unemployment at the community level or by living in the South (traditionally, the area with the poorest situation in the labour market). 


\section{Data description and first analyses}

In this part, we briefly describe the individual, household, and municipality level data sources and variables we use in subsequent analyses. We then perform a descriptive analysis in order to draw a preliminary picture of the young adults who LAT with their parents.

\subsection{Data sources and variables}

We use individual and household level data from 1998 Multipurpose Survey on "Households, Social Subjects and Childhood Conditions", conducted by the Italian National Institute of Statistics. In this survey, a special section was devoted to the study of living arrangements of young people including LAT. Municipality level data have been built starting from the 1991 population census, and they have been linked to the survey data.

The target population of the survey is composed by all residents in Italy, excluding the permanent residents of institutions. It has a two stage sampling scheme. At the first stage, a stratified sample of municipalities is drawn. The stratification of municipalities is by geographical area and population size. At the second stage, within the selected municipalities, a random sample of households is selected using local population registers. For each household included in the sample, an interviewer administered questionnaire is administered in order to gather information about all members of the household (in the de facto status), in addition to general information about household characteristics (which allows to link to each individual the data on the resident parents, children and siblings for instance). 816 municipalities have been selected, and 
information has been gathered on 20,153 households. The total number of individuals is then 59,050. We focus our attention on young adults aged 15-34 who coreside with at least one parent. By design, in each household all resident siblings who are aged 15-34 enter our analyses.

The propensity to LAT has been investigated by a specific section of the questionnaire. Each member of the household was asked whether, in the course of the last year, he or she has, with a certain regularity (for instance two days a week, or the whole week excluding the weekend, or again during a university term, excluding holidays and business trips), lived in a different dwelling with respect to the one where he/she is residing with the other members of the household. Those who answered affirmatively were asked for the total length of stay outside the main dwelling, the place of sojourn, the living arrangement and the type of dwelling, the financing of the stay and the main motivations of the stay (including multiple motivations).

A set of variables relates to the individual level. Occupational status is recoded to distinguish three statuses: employed, students, in other conditions. We further distinguished students among university students (i.e. those who are currently enrolled at a university), and other students. Stated reasons for LAT have been divided in four categories: job related, study related, family related (i.e. those related to a relationship with a partner, with parents, with children, siblings or other relatives), and others (all other reasons including for example health, military or community service, individual autonomy). Living arrangements outside the parental household include the following statuses: alone, with colleagues/students, with friends, with relatives (i.e. those who lived with a partner, a parent, children, and other relatives). The place of stay during the period not spent in the parental home has been categorised according to the distance to 
the place of residence of parents: in the same municipality, in another municipality of the same province, in another province of the same region, in another Italian region, abroad, in several places. Finally, the sources of financial support are distinguished between own income, help from parents and other relatives, help from hosting household, income from scholarship, help from employer, and other reasons.

An additional set of variables refers to the household level and used in the statistical models. Among household types, single parents are considered separately from households in which both parents are present. Education as a measure of cultural capital is the highest level among the parents (three categories: elementary or lower; primary school; high school or higher). Employment status of the father (of the mother if she is a single parent) is used as a proxy of social class: the categories are non manual worker, self employed, manual worker, other. A crowding index of the flat has been computed dividing the number of individuals by the number of rooms. An important indicator is whether parents own (at least a) a second flat: an indicator of wealth; moreover the second flat might be the one used to LAT (although this exact information is not available to us).

In addition to the individual and household level data, we could link, for each of the 816 municipalities sampled in the survey, data at the municipality level. We used the following variables: 1) an ageing index, computed as the (percent) ratio of the resident population aged 65 and over with respect to the resident population aged 14 and younger; 2) the unemployment rate; 3) an indicator of the rank of the employed population, as the proportion of managers, white collars and entrepreneurs with respect to the total active population. 


\subsection{LAT with parents in Italy: a descriptive picture}

In 1998, more than ten million young Italians aged 15-34 years live with their parents and are classified as "children", that is, they have never had an own family. If we analyse the labour market status of young adults living with their parents, we notice that only in the age interval 15-19 students are the absolute majority (71.4\% of men and $74.7 \%$ of women). At ages between 20 and 24 years, the most important group among men is that of employed, followed by other conditions (including military service, unemployed, housework) and then by students. For women, students are still the most important group, followed by other conditions and only then by employed. At older ages, the share of employed rises considerably (Table 2).

Broadly speaking, men are overrepresented among those who are employed and living with their parents: this state accounts for $41.8 \%$ of men against $28.2 \%$ for women. Such gender differentials are also persistent in the older age classes: between the ages of 30 and $34,77.9 \%$ of men and $65.1 \%$ of women living with their parents are employed. The reverse is true for students. For instance, in ages $20-24,35.7 \%$ of young women living with their parents are students against $22.9 \%$ of young men.

We now use some of the additional questions on young adults who LAT with parents to get more information on their condition. The vast majority of young adults who are employed and LAT with their parents lives away from their parents for job related reasons, though a substantial part declares the main reason to be living with a family member or a partner. Job related reasons for LAT with parents are equally referred to for men $(70.5 \%$ and for women $(71.1 \%)$. In the employed group, women more often 
quote family related reasons (19\% with respect to $10.6 \%$ for men). Among students who LAT with their parents, almost all of them have live away for study related reasons. There is little space for other reasons, and there are no evident gender differences (Table 3).

What are the living arrangements of LAT youth while not living with their parents? Table 4 reports the answer to a specific question on this issue. There are important gender differences among the employed: women more often live with a relative, while men more often live with colleagues. On the other hand, when students live away from their parents they mostly live with other students or with friends. A significantly lower share of students lives with relatives or alone.

The distance of moves away from parents varies substantially for the employed. On the contrary, students tend more often to move within the same region. Men tend to move further away with respect to women (Table 5).

The total duration of permanence away from parents is also very heterogeneous. Of those who are registered with parents at the time of interview, more than half has stayed more than 150 days away in a year. Nevertheless, about a quarter of young employed men and more than a third of young employed women moves for no more than 90 days. For students, the duration of permanence away from parents is usually longer: for them more than three fifths lives away more than 150 days (Table 6).

As we could expect, income sources are different according to employment status. Employed young adults can earn usually enough money for themselves. Nevertheless, $28.3 \%$ of employed young women, and $13.6 \%$ of employed young men receive help from their parents. Students live, in the vast majority of cases, at their parents' expenses 
(90\% of the cases). Only a minority of them has access to scholarships or has other sources of income (Table 7).

This descriptive picture reinforces the view that LAT with parents is an opportunity especially for university students (given for instance the support they receive from parents). Constraints may play a more prominent role for employed—some of them still report transfers from parents or others as a source of income.

\section{TABLES 2-7 ABOUT HERE}

\section{Methods: a three level probit model}

We now move towards the analysis of the determinants of LAT with parents. Our modelling strategy is based on a multilevel probit model. The three levels considered are the individual level; the household level (all young adults who reside in the same household are supposed to share observed and unobserved household factors); the community level (all households residing in a community are supposed to share observed and unobserved community factors). The number of observations does allow us to estimate a community level effect (including unobserved factors), while more aggregated regional variables (areas) are used as explanatory factors.

It is well known that a probit regression model can be interpreted within a latent variable (or random utility) framework. In our case, the latent dependent variable (say, $\left.y^{*}\right)$ is the propensity to LAT with parents. However, we do not observe the propensity, but the actual behaviour, a binary variable (say, y) indicating whether individuals 
actually LAT (associated to positive values of the LAT propensity $y^{*}$ ) or reside permanently with parents (associated to zero or negative values of the LAT propensity $\left.y^{*}\right)$. In a regression model, the propensity to LAT with parents is seen as a function of both observed and unobserved factors. In a multilevel probit regression model, observed and unobserved factors belong to different levels of aggregation.

More specifically, in our case, we have a three level structure for the latent propensity to LAT for an individual $k$, living in a household $j$, in a municipality $i$. The propensity is a function of observed variables at the individual level $a_{i j k}$, at the household level, $b_{i j}$, at the community level, $c_{i}$, and of unobserved variables, or residuals, that are assumed to be normally distributed, at the individual level $u_{i j k}$, at the household level, $v_{i j}$, at the community level, $z_{i}$. The variance of the individual level unobserved variable is set to unity to avoid identification problems. Additionally, as it is usually done within a multilevel modelling framework, residuals are hypothesised to be mutually independent. The equation of the model is thus:

$y_{i j k}^{*}=a_{i j k} \alpha+b_{i j} \beta+c_{i} \gamma+u_{i j k}+v_{i j}+z_{i}$

where $u_{i j k} \sim N(0,1), v_{i j} \sim N\left(0, \sigma_{v}^{2}\right), z_{i} \sim N\left(0, \sigma_{z}^{2}\right)$

The fact that equation (1) expresses a latent relationship implies that we do not observe the actual values of $y_{t}^{*}$. Instead we observe its sign, which will determine the value of the observed binary variable

$y_{i j k}=\operatorname{Pr}\left(y_{i j k}^{*}>0\right)$ 


\section{Results}

The results of the estimated models are presented in table 7 . We interpret and discuss the results separately for students and employed young adults.

\subsection{Students}

The baseline model indicates that only age matters among our individual level observed variables, although the pattern is not monotonically rising but peaks at ages 22-24. There are statistically significant random components at the household (estimated s.d.=1.58) and at the municipality (estimated s.d.=1.78) level; this indicates that household level and municipality level variables can indeed contribute to the explanation of LAT with parents.

In the second step (final model) we introduce household level and community level variables, the residual variance is reduced but remains still present and significantly different from zero (household s.d.=1.44, community s.d.=1.16). First we can notice the 
contribution of observed variables to the explanation of residual variability at both levels: the observed variables we introduce explain $16.9 \%$ of the household level variance and $57.5 \%$ of the community level variance. Indeed, the final model is able to "explain" better the influence of the community level than the influence of the household level.

Let us now discuss the results of the final model in detail for each level and compare them with the empirical hypotheses we cast in section 4.

Individual level. The effect of age has an inverted $U$ shape rather than a monotonically increasing shape; this goes against our original hypothesis connected to the rising desire of independence with age. Selection problems may however guide this effect, as being a university student after age 24 implies lagging behind "standard" calendars. It is very interesting to note that gender differentials vary by area (see also figure 1). This is consistent with the hypothesised interaction between gender and region: Southern Italian young women may be hampered in their propensity to attend universities far away, and to exploit LAT with parents in order to pursue education away from their place of residence, from home because of the lack of parental support. This support is however on average given to their (eventual) brothers. This result is in particular in line with the higher level of parental control to which young women in Southern Italy are subject with respect to young men (see e.g. Rosina and Rivellini, 2004).

Household level. The household type has no significant influence on the propensity to LAT. In line with our hypothesis, youth's propensity to LAT is positively related to parental cultural resources and wealth: the propensity to LAT is significantly higher when parents have high school or higher education, or if they own a second flat. 
Owning a second flat may be seen as endogenous; however, omitting this variable does not change the impact of other variables. However, the effect of social class is not significant (although the general categories we could use might be insufficient to catch social class effects).

Municipality level. Living in the South and Islands increases the propensity to LAT with parents. Also, living in a small community, or outside urban areas increases the propensity to LAT. This result is consistent with our hypothesis that sees LAT as a key opportunity to access to higher education away from the parental place of residence within the Italian general setting in which university residences are scarce. These factors, as we have seen, contribute in a significant way to explain community level variability. Moreover, other community level variables (related to ageing or to the labour market) do not have a statistically significant effect.

\subsection{Employed}

The baseline model indicates that age matters among our individual level observed variables, with a monotonically rising pattern. There are statistically significant random components at the household (estimated s.d. $=0.69$ ) and at the municipality (estimated s.d.=0.49) level; this indicates that household-level and municipality-level variables can indeed contribute to the explanation of LAT with parents. However, their relevance is lower with respect to the case of university students-individual level factors explain relatively better the propensity to LAT in this case.

When we introduce household level and community level variables (final model), the residual variance is only marginally reduced for the household level $(\mathrm{s} . \mathrm{d}=0.69)$ while 
the reduction is higher for the community level (s.d.=0.40). This is reflected in the contribution of observed variables to the explanation of residual variability at both levels: the variables we introduce explain only $1.9 \%$ of the household level variance while they explain $51.9 \%$ of the community level variance. Let us now discuss the results of the final model, separately for each level.

Individual level. The propensity to LAT rises with age, in line with our hypothesis. Gender differentials and the interaction between gender and geographical area have effects in a similar direction with our hypothesis (and with the results on university students); however, their effect is not statistically significant. Parental and social constraints seem thus less stringent when LAT is connected to job related choices and constraints. We might speculate that the opportunity of earning an income raises the bargaining power of a daughter within a family. Within lower social strata, young women might be pushed towards low paid jobs especially when financial needs arise.

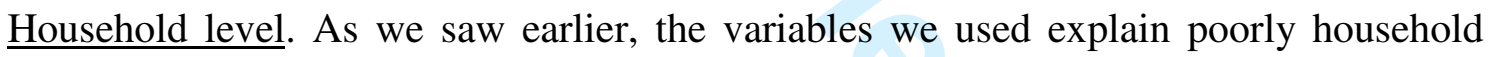
level determinants of LAT with parents for employed young adults. Nevertheless, higher cultural capital is still significantly related to a higher propensity to LAT.

Municipality level. The variables we use explain a relatively high share of community level variability. The variables that are statistically significant are related to situation in the labour market, in accordance with our hypotheses. Residing in the South and Islands (as we said, traditionally a poorer labour market at the regional level) increases the probability to LAT. Moreover, the propensity to LAT is significantly higher when young adults reside with parents in municipalities with a higher unemployment rate. The size of the municipality and its location in a metropolitan area are not statistically 
significant, nor are significant the effects of ageing and of the community level social class.

\section{TABLE 8 ABOUT HERE}

FIGURE 1 ABOUT HERE

\section{Summary and concluding remarks}

In this paper we introduced the idea that the LAT concept can be fruitful for the analysis of young adults' relationship with parents, and not only for couple relationships. This is particularly relevant in the new context where educational expansion has contributed to "institutionalise" a long transition to adulthood, while individualisation has triggered off the emergence of new statuses (of which LAT is an example, although potentially with historical antecedents) and pathways to adulthood.

LAT with parents is particularly relevant in a context like Italy, where young adults leave the parental home at very late ages in a comparative perspective, and the vast majority of university students as well as a sizable share of employed young adults resides with parents. Besides a description of young adults who LAT, we cast some empirical hypotheses on the determinants of such behaviour. The propensity to LAT has been considered as depending on individual, household, and community level factors. 
We analysed the propensity to LAT using a linked dataset of survey and census data. Our analyses are based on a set of three level probit statistical models, separately fitted for students and employed young adults. The results show that beyond individual level factors, household and municipality level factors matter significantly on the propensity of young adults to LAT with their parents. The relative weight is different according to the status of the young adult: household and municipality level factors are more relevant in the case of students, while individual level and municipality level factors appear as relatively more relevant in the case of employed.

Most of the empirical hypotheses we developed starting from the literature were supported by the results. Age matters in LAT choices, although only for employed youth who reside with parents the propensity to LAT clearly increases with age. Gender matters, but only in interaction with the geographical area: as we see LAT as an opportunity women from the South-Island area have a lower opportunity to access it. The consideration of LAT as an opportunity is reinforced by the result that parental cultural capital and wealth influence positively the propensity to LAT. Municipality factors also matters in a significant way, although differently for students and employed youth. For university students, accessibility to university seems a key issue-geography matters-LAT is a resource in a country in which distances are long but not impeding some periodic movement. For employed youth, the situation of the labour market in the municipality of origin pushes towards LAT — a sign that, although LAT may be seen mainly as an opportunity, constraints such as job availability also play an important role.

While our findings confirm the view in the literature that young Italian adults live longer with their parents both because of choice and because of constraints, LAT seems 
to be considered more as a new opportunity in a land of the "latest late" transition to adulthood. We are not however in the position to affirm that the propensity to LAT counterbalances the long permanence of young adults with their parents in Italy. Future research will have to become longitudinal, when data become available, to address the stability of LAT living arrangements, and to address issues related to selectivity. Geographical Information Systems might also help in understanding more the geographical determinants. Comparative analyses on the topic might also shed light on the specificity of the Italian situation. 


\section{Bibliographic references}

AASSVE, A., F.C. BILLARI, F. ONGARO. 2001. The impact of income and employment status on leaving home: evidence from the Italian ECHP sample. Labour: Review of Labour Economics and Industrial Relations, 15 (3): 501-529.

BARBAGLI, M., M. CASTIGLIONI, G. DALLA ZUANNA. 2003. Fare famiglia in Italia. Un secolo di cambiamenti. Bologna: il Mulino.

BECK U. 1992. Risk Society. London: Sage.

BECK U., E. BECK-GERNSHEIM. 1995. The Normal Chaos of Love. Cambridge, UK: Polity Press.

BECK U., E. BECK-GERNSHEIM. 2002. Individualisation: Institutionalized individualism and Its Social and Political Consequences. London: Sage.

BILLARI F.C. 2004. Becoming an Adult in Europe: A Macro(/Micro)-Demographic Perspective. Demographic Research, Special Collection 3 - Article 2: 13-44.

BILLARI F.C., A. ROSINA. 2004. Italian "latest-late" transition to adulthood: an exploration of its consequences on fertility. Genus, LX (1): 71-88.

BILlARI, F.C., D. PHILIPOV, P. BAIZÁN. 2001. Leaving home in Europe: the experience of cohorts born around 1960. International Journal of Population Geography, 7, 5: 339-356.

BILLARI F.C, M. CASTIGLIONI, T. CASTRO MARTİN, F. MICHIELIN, F. ONGARO. 2002. Household and Union Formation in a Mediterranean Fashion: Italy and Spain. In 
E. Klijzing, M. Corijn (Eds.), Fertility and partnership in Europe: findings and lessons from comparative research. Volume II. New York and Geneva: United Nations, 17-41.

BORGONI, R., F.C. BILLARI. 2001. Spatial Discrete-Time Event History Models: An Application to Home-Leaving. In C. PROVASI (Ed.), Modelli complessi e metodi computazionali intensivi per la stima e la previsione. Padova: Cleup editrice.

BUCHMANN M. 1989. The Script of Life in Modern Society. Entry into Adulthood in a Changing World. Chicago: University of Chicago Press.

CAVAlli A., O. GALLAND (Eds.). 1995. Youth in Europe. Social Change in Western Europe. London: Pinter.

DALLA ZUANNA G., G.A.MICHELI (Eds.), Strong family and low fertility: a paradox? Dordrecht: Kluwer Academic Press.

DA MOLIN G. 1990. Family Forms and Domestic Service in Southern Italy from the Seventeenth to the Nineteenth Centuries. Journal of Family History, 15: 503-527.

DE SANDRE P. 1988. Quando i figli lasciano la famiglia. In Scabini E., Donati P. (a cura di), La famiglia "lunga" del giovane adulto. Verso nuovi compiti evolutivi, Vita e Pensiero, Milano.

ELIASSON K., U. LINDGREN, O. WESTERLUND. 2003. Geographical Labour Mobility: Migration or Commuting?. Regional Studies, 37 (8): 827-837.

ELZINGA C., A.C. LIEFBROER. 2006. De-Standardization and Differentiation of Family Life Trajectories of Young Adults: A Cross-National Comparison. Paper presented at 
the IUSSP Workshop on Transitions to Adulthood, 15-17 June 2006, McGill University, Montréal, Canada.

GIDDENS A. 1990. The Consequences of Modernity. Polity Press: Cambridge.

GOLDSCHEIDER, F.K., J. DAVANZO. 1986. Semiautonomy and Leaving Home in Early Adulthood. Social Forces, 65 (1): 187-201.

FERNANDEZ CORDON, J. A. 1997. Youth residential independence and autonomy: a comparative study. Journal of Family Issues, 16 (6): 567-607.

HOLDSWORTH C., D. VOAS, M. TRANMER. 2002. Leaving home in Spain: When, where and why? Regional Studies, 36 (9): 989-1004.

HUBER P.J. 1967. The Behavior of Maximum Likelihood Estimates under Non-Standard Conditions. In: Proceedings of the Fifth Berkeley Symposium on Mathematical Statistics and Probability, Berkeley, California: University of California Press: Vol. 1: 221-233.

JONES G. 1995. Leaving home, Open University Press, Buckingham - Philadelphia.

LASLETT P. 1977. Family Life and Illicit Love in Earlier Generations, Cambridge University Press, Cambridge.

LEVIN I. 2004. Living Apart Together: A New Family Form. Current Sociology, 52(2): 223-240.

LILLARD L.A., C.W.A. PANIS. 2000. aML Multilevel Multiprocess Statistical Software, Release 1.0, Econware, Los Angeles, California. 
LUNDH C. 2003. Life Cycle Servants in Nineteenth Century Sweden-Norms and Practice, Lund Papers in Economic History, No. 84, 2003, Deparment of Economic History, Lund University, Lund.

MAYER K.U., W. MÜLLER. 1986. The State and the Structure of the Life Course. In: A.B. Sorensen, F.E. Weinert and L.R. Sherrod (eds.) Human Development and the Life Course: Multidisciplinary Perspectives. Hillsdale, NJ: Lawrence Erlbaum Associates Publishers: $217-245$

MODELL J., F.F. FURSTENBERG, T. HERSHBERG. 1976. Social Change and Transitions to Adulthood in Historical Perspective. Journal of Family History, 1: 7-32..

PATINIOTIS J., C. HOLDSWORTH. 2005. 'Seize That Chance!' Leaving Home and Transitions to Higher Education. Journal of Youth Studies, 8 (1): 81-95.

REHER D. 1998. Family Ties in Western Europe: Persistent Contrasts. Population and Development Review, 24: 203-234.

ROSINA A., G. RIVELLINI. 2004. Living arrangements, trasgressive behaviour and sexuality. In C. Crisafulli and G. Dalla Zuanna (eds.), Sex and the Italian Students, University of Messina, Department of Statistics.

SCHIZZEROTTO A., M. LUCCHINI. 2002. Transitions to Adulthood during the Twentieth Century. A comparison of Great Britain, Italy and Sweden. EPAG Working Paper 2002-36. Colchester: University of Essex, November 2002.

SMITH R.M. 1981. The People of Tuscany and Their Families in the Fifteenth Century: Medieval or Mediterranean? Journal of Family History, 6: 107-128. 
VALENTINE G. 2003. Boundary Crossings: Transitions from Childhood to Adulthood. Children's Geographies, 1(1): 37-52.

VIAZZO P.P. 2003. What's so special about the Mediterranean? Thirty years of research on household and family in Italy. Continuity and Change, 18(1): 111-137.

VILLENEUVE-GOKALP C. 2000. Les jeunes partent toujours au même âge de chez leurs parents. Économie et Statistique, 337-338: 61-80.

WALTHER A., B. STAUBER, A. BIGGART, M. DU BOIS-REYMOND, A. FURLONG, A. LÓPEZ BLASCO, S. MOERCH, J.M. PAIS (Eds.). 2002. Misleading Trajectories Integration Policies for Young Adults in Europe? An EGRIS Publication. Opladen, Leske+Budrich. 


\section{Young adults living apart and together (LAT) with parents:}

\section{a three-level analysis of the Italian case}

\section{Tables and figures}

Table 1. Young adults aged 15-34 who reside with their parents by occupational status, LAT status and gender (\%).

\begin{tabular}{|l|r|r|r|r|r|r|r|r|}
\hline & \multicolumn{2}{|c|}{ Men } & \multicolumn{2}{l|}{ Women } & \\
\hline & Employed & $\begin{array}{r}\text { University } \\
\text { student }\end{array}$ & $\begin{array}{r}\text { Other } \\
\text { student }\end{array}$ & Other & Employed & $\begin{array}{r}\text { University } \\
\text { student }\end{array}$ & $\begin{array}{r}\text { Other } \\
\text { student }\end{array}$ & Other \\
\hline & & & & & & & & \\
\hline LAT & 9.3 & 23.3 & 3.2 & 12.8 & 6.6 & 23.4 & 3.0 & 5.6 \\
\hline $\begin{array}{l}\text { Permanen } \\
\text { t resident } \\
\text { (not LAT) }\end{array}$ & 90.7 & 76.7 & 96.8 & 87.2 & 93.4 & 76.6 & 97.0 & 94.4 \\
\hline$N$ & 2,389 & 695 & 1,314 & 1,315 & 1,265 & 868 & 1,283 & 1,061 \\
\hline
\end{tabular}

Note: column total is $100 \%$. 
Table 2. Young who reside with their parents by occupational status, age and gender (\%).

\begin{tabular}{|c|c|c|c|c|c|c|c|c|}
\hline \multirow[t]{2}{*}{ Age } & \multicolumn{4}{|l|}{ Men } & \multicolumn{4}{|l|}{ Women } \\
\hline & Employed & $\begin{array}{r}\text { University } \\
\text { student }\end{array}$ & $\begin{array}{r}\text { Other } \\
\text { student }\end{array}$ & Other & Employed & $\begin{array}{r}\text { University } \\
\text { student }\end{array}$ & $\begin{array}{r}\text { Other } \\
\text { student }\end{array}$ & Other \\
\hline & & & & & & & & \\
\hline 15-19 & 10.7 & 3.8 & 71.4 & 14.1 & 5.0 & 7.0 & 74.7 & 13.4 \\
\hline $20-24$ & 39.1 & 22.9 & 5.9 & 32.1 & 29.7 & 35.7 & 4.5 & 30.1 \\
\hline $25-29$ & 61.6 & 11.8 & 2.2 & 24.4 & 50.7 & 18.3 & 3.2 & 27.8 \\
\hline $30-34$ & 77.9 & 4.6 & 0.3 & 17.1 & 65.1 & 4.8 & 0.2 & 29.9 \\
\hline Total & 41.8 & 12.2 & 23.0 & 23.0 & 28.2 & 19.4 & 28.7 & 23.7 \\
\hline & & & & 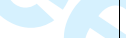 & & & & \\
\hline
\end{tabular}

Note: row total is $100 \%$. For sample size see table 1. 
Table 3. Young adults who LAT with their parents by gender, employment status and stated reasons for LAT (\%).

\begin{tabular}{|c|c|c|c|c|c|}
\hline \multirow[t]{2}{*}{ Reasons } & \multicolumn{3}{|c|}{ Employed } & \multicolumn{2}{|c|}{ University student } \\
\hline & Men & 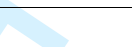 & Women & Men & Women \\
\hline & & s. & & & \\
\hline Job-related & 70.5 & $(\gamma$ & 71.1 & 1.1 & 2.0 \\
\hline Study-related & 4.1 & 5 & 20.1 & 93.5 & 97.0 \\
\hline Family-related & 10.6 & 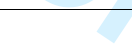 & 19.0 & 1.6 & 2.0 \\
\hline Other & 22.1 & & 6.8 & 5.8 & 2.4 \\
\hline$N$ & 222 & & 84 & 162 & 203 \\
\hline
\end{tabular}

Note: multiple answers were possible. 


\section{Page 39 of 45}

\section{Regional Studies}

Table 4. Young adults LAT with their parents by living arrangement when they live away from their parents (\%).

\begin{tabular}{|c|c|c|c|c|}
\hline \multirow{2}{*}{$\begin{array}{l}\text { Living } \\
\text { arrangem } \\
\text { ent }\end{array}$} & \multicolumn{2}{|c|}{ Employed } & \multicolumn{2}{|c|}{ University student } \\
\hline & Men & Women & Men & Women \\
\hline & & & & \\
\hline Alone & 29.8 & 31.7 & 7.5 & 5.9 \\
\hline $\begin{array}{l}\text { With } \\
\text { colleague } \\
\text { s/ } \\
\text { students }\end{array}$ & 40.5 & 17.9 & 65.5 & 62.9 \\
\hline $\begin{array}{l}\text { With } \\
\text { friends }\end{array}$ & 12.2 & 23.4 & 20.3 & 18.6 \\
\hline $\begin{array}{l}\text { With } \\
\text { relatives }\end{array}$ & 22.0 & 28.6 & 9.3 & 11.4 \\
\hline Other & 3.1 & 3.4 & 2.2 & 2.9 \\
\hline
\end{tabular}

Note: column total is $100 \%$. For sample size see Table 3. 
Table 5. Young adults LAT with their parents by place of domicile when they live away from their parents (\%).

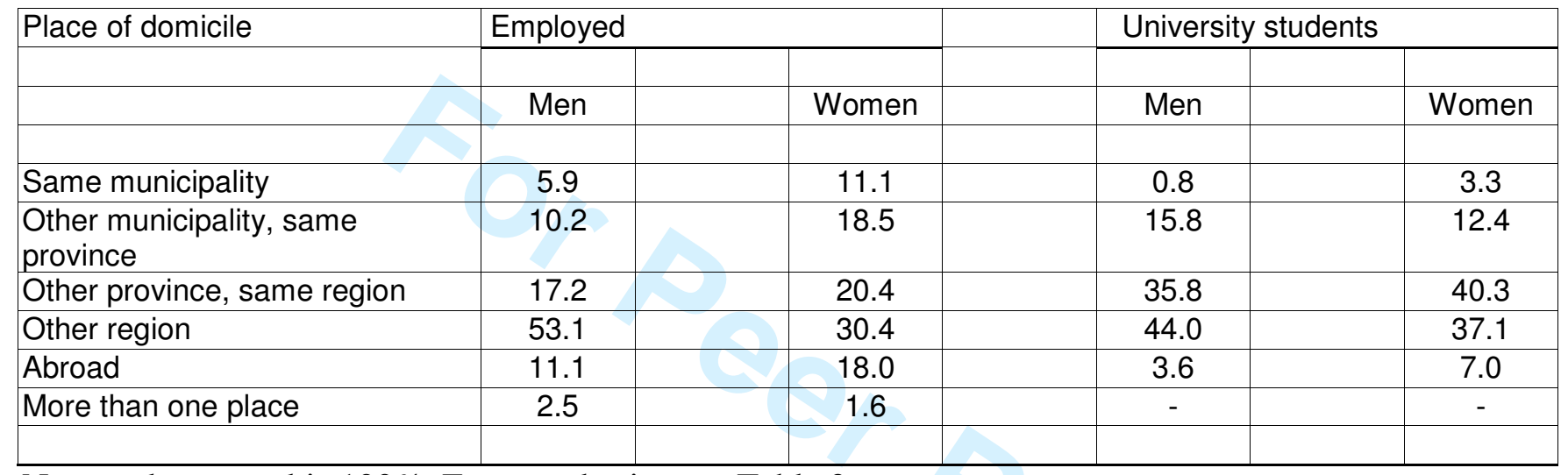

Note: column total is $100 \%$. For sample size see Table 3. 


\section{Page 41 of 45}

\section{Regional Studies}

Table 6. Total length of permanence away from their parents for young adults LAT with their parents (\%).

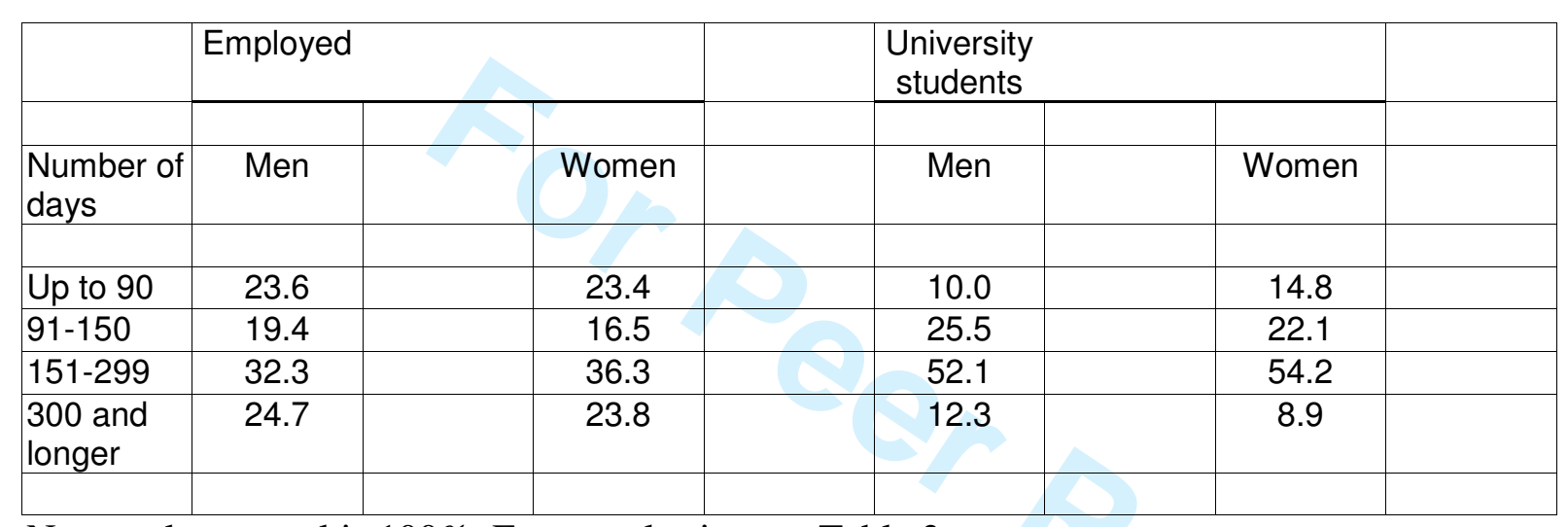

Note: column total is $100 \%$. For sample size see Table 3. 
Table 7. Source of income for young adults LAT with their parents (\%).

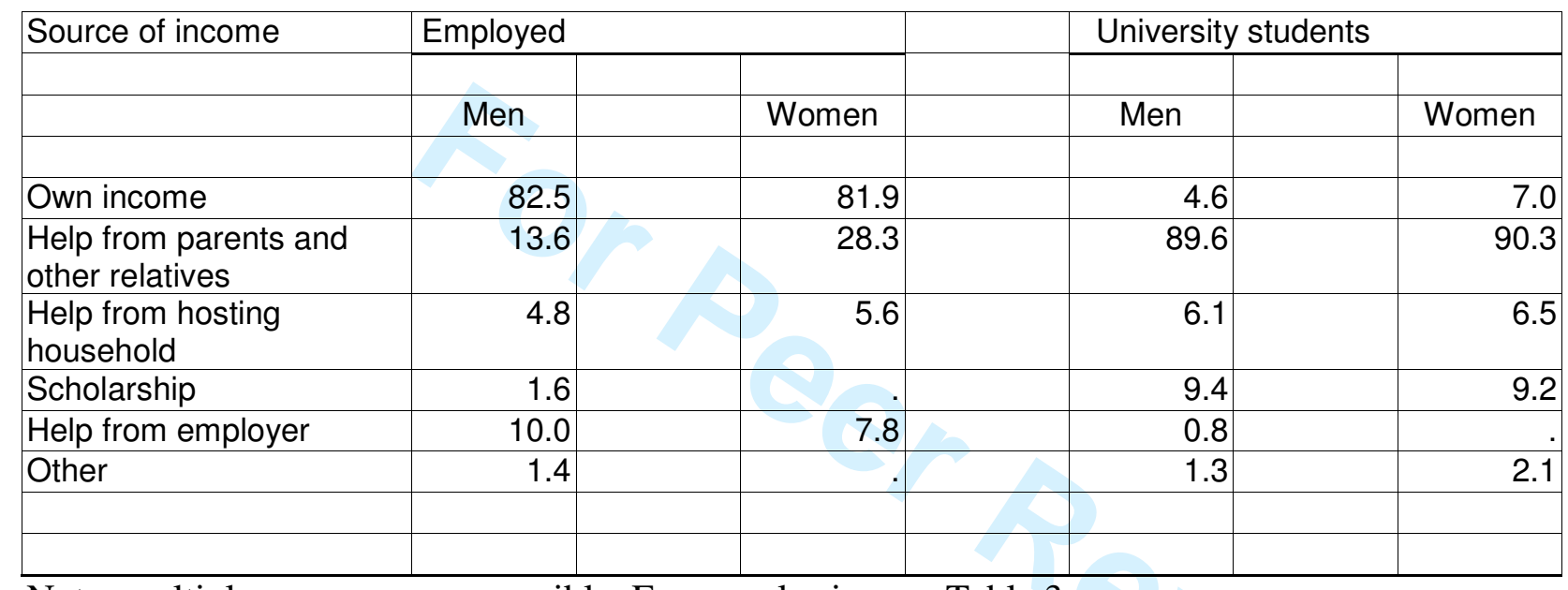

Note: multiple answers were possible. For sample size see Table 3. 
Table 8. Estimates of the three-level probit models on the propensity to LAT.

\section{UNIVERSITY STUDENTS}

Baseline model Final model

\section{EMPLOYED}

Baseline model

Final model

\begin{tabular}{|c|c|c|c|c|c|c|c|c|}
\hline \multicolumn{9}{|l|}{ INDIVIDUAL LEVEL } \\
\hline Constant & $-1.4575 * * *$ & $(0.2571)$ & -0.2561 & $(0.8708)$ & $-2.1753 * * *$ & $(0.2281)$ & $-2.5719 * * *$ & $(0.4419)$ \\
\hline \multicolumn{9}{|l|}{ Gender } \\
\hline Man (reference) & 0 & 0 & 0 & 0 & 0 & 0 & 0 & 0 \\
\hline Woman & -0.1533 & $(0.1547)$ & $-0.6697 * *$ & $(0.2929)$ & -0.0801 & $(0.0965)$ & -0.3303 & $(0.2897)$ \\
\hline \multicolumn{9}{|l|}{ Age } \\
\hline 19-21 (reference) & 0 & 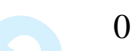 & 0 & 0 & 0 & 0 & 0 & 0 \\
\hline $22-24$ & $0.3104 *$ & $(0.1615)$ & $0.2522 *$ & $(0.1517)$ & -0.005 & $(0.1369)$ & -0.0767 & $(0.1447)$ \\
\hline $25-27$ & 0.2601 & $(0.2106)$ & 0.3129 & $(0.1999)$ & $0.265 *$ & $(0.1376)$ & 0.156 & $(0.1424)$ \\
\hline $28+$ & 0.1583 & $(0.3052)$ & 0.0927 & $(0.2852)$ & $0.403 * * *$ & $(0.1290)$ & $0.3255 * *$ & $(0.1362)$ \\
\hline \multicolumn{9}{|l|}{ HOUSEHOLD LEVEL } \\
\hline \multicolumn{9}{|l|}{ Household type } \\
\hline Single parent & & & -0.0767 & $(0.2789)$ & & & -0.0566 & $(0.1269)$ \\
\hline Both parents (reference) & & & 0 & 0 & & & 0 & 0 \\
\hline \multicolumn{9}{|l|}{ Education } \\
\hline High school or higher & & & $0.5261 * *$ & $(0.2621)$ & & & $0.4966 * * *$ & $(0.1465)$ \\
\hline Primary school & & & 0.118 & $(0.2402)$ & & & $0.2087 * *$ & $(0.1022)$ \\
\hline Elementary or lower (reference) & & & 0 & 0 & & & 0 & 0 \\
\hline \multicolumn{9}{|c|}{$\begin{array}{l}\text { Employment status of the father (mother } \\
\text { if father is absent) }\end{array}$} \\
\hline Non-manual worker & & & -0.1294 & $(0.2268)$ & & & 0.14 & $(0.1305)$ \\
\hline Self-employed & & & -0.0183 & $(0.2338)$ & & & 0.0834 & $(0.1244)$ \\
\hline Manual worker & & & 0 & 0 & & & 0 & 0 \\
\hline Other/died & & & -0.5923 & $(0.3919)$ & & & $-0.5455 * *$ & $(0.2264)$ \\
\hline Crowding index for the flat & & & -0.2577 & $(0.3042)$ & & & 0.0343 & $(0.1496)$ \\
\hline \multicolumn{9}{|l|}{ The household owns a second flat } \\
\hline Yes & & & $0.4571 * * *$ & $(0.1677)$ & & & 0.1572 & $(0.0958)$ \\
\hline No (reference) & & & 0 & 0 & & & 0 & 0 \\
\hline
\end{tabular}


Table 8. Estimates of the three-level probit models on the propensity to LAT.

\section{MUNICIPALITY LEVEL}

Geographical area

North-Centre

South

Islands (reference)

Interaction area*gender

North-Centre*Woman

South*Woman

Islands*Woman

Population of the municipality

Up to 10,000 inhabitants

10,000-50,000 inhabitants.

50,000 and more inhabitants (non-

metropolitan area).

Metropolitan area

Unemployment rate $(\%)$

Ageing index (\%)

High rank employed population (\%)

$-2.3506 * * * \quad(0.5414)$

$-1.0823 * *$

0

$0.8651 * *$

0.4357

(0.3641)

(0.3576)

$1.4439 * * * \quad(0.3694)$

$0.9375 * * * \quad(0.3121)$

0

$-2.1859 * * * \quad(0.5476)$

$-0.0214 \quad(0.0135)$

$0.002 \quad(0.0019)$

$-0.0036$

(0.0268)
$-0.4638 *$

$-0.0115$

$(0.2440)$

$(0.1882)$

0

0.5087

$-0.2143$

$(0.3120)$

0

(0.3743)

0.1178

$-0.0495$

$(0.1560)$

0

$-0.2513$

$0.0236 * * * \quad(0.0077)$

$0.0009 \quad(0.0009)$

$0.0043 \quad(0.0122)$

\section{RESIDUAL VARIANCE}

COMPONENTS

Household level

Estimated residual s.d.

Municipality level

Estimated residual s.d.

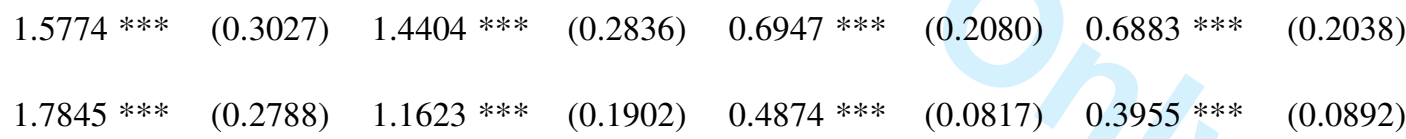

Number of cases

-876.98
1658

-797.25
1658

1658
$-845.27$
3687

$-793.62$

Number of events

468

468

232

232 


\section{Figures}

Figure 1. Effects of gender and area of residence on the propensity to LAT for students (reference: men living in the Islands).

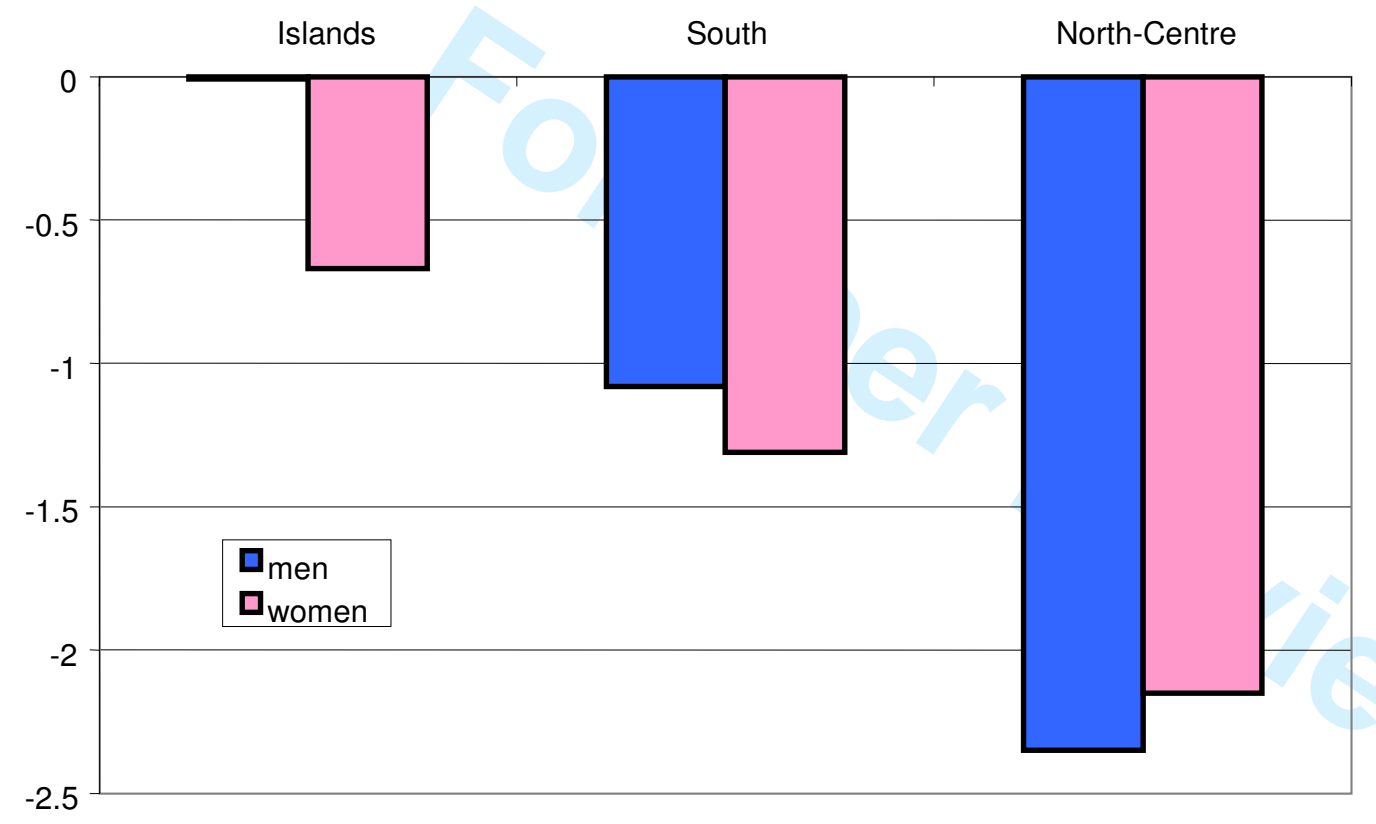

